\title{
"Air" on the side of caution: The importance of early recognition and intervention in Ludwig's angina
}

\author{
Sallie M. Long*1, Talha Demirci ${ }^{2}$, Stacy R. Kruse ${ }^{1,2}$ \\ ${ }^{1}$ Georgetown University, School of Medicine, Washington, D.C., USA \\ ${ }^{2}$ Department of Medicine, MedStar Georgetown University Hospital, Washington, D.C., USA
}

Received: June 13, 2018

DOI: $10.5430 /$ crim.v5n3p40
Accepted: July 29, 2018

URL: https://doi.org/10.5430/crim.v5n3p40

\begin{abstract}
Ludwig's angina is a deep neck infection of the supramylohyoid and inframylohyoid spaces. Without prompt recognition and intervention, it can progress to airway compromise with significant morbidity and mortality. Although otolaryngologists and oral surgeons are well-versed in this condition, it is vital that physicians across all specialties are knowledgeable about the presentation and basic treatment of this potentially fatal condition. Here we report a case of Ludwig's angina in a 29-year-old male that was successfully managed with both medical and surgical intervention. We also aim to describe the presentation and treatment of Ludwig's angina in order to increase awareness in non-surgical fields.
\end{abstract}

Key Words: Ludwig's angina, Deep neck infection, Critical care, Infectious disease

\section{INTRODUCTION}

Ludwig's angina is a deep neck infection of the spaces above and below the mylohyoid muscle. Ludwig refers to Wilhelm Friedrich von Ludwig who described it in 1836. ${ }^{[1,2]}$ Angina originates from the Latin and Greek roots for "choke" and "strangle", which corresponds to the devastating airway obstruction that can occur in these cases. ${ }^{[1]}$ Infection may also spread within the deep planes of the neck resulting in complications such as mediastinitis and necrotizing fasciitis. ${ }^{[3-6]}$

Ludwig's angina is usually a sequela of odontogenic infection. The source is often the second and third mandibular molars and expands into a bilateral cellulitis of the sublingual and submandibular areas. ${ }^{[1]}$ In addition to constitutional symptoms, patients may endorse trismus, or the inability to move the jaw. ${ }^{[1]}$ The maximum interincisal distance is thus important to measure and follow on physical exam. Dys- phagia, painful tongue movement, and otalgia may also be seen. It is critical to identify signs of respiratory distress such as dyspnea, tachypnea, dysphonia or stridor. ${ }^{[1]}$ Physical exam findings may include macroglossia and tense bilateral swelling in the floor of mouth and submandibular region. ${ }^{[1,4]}$

Ludwig's angina is a clinical diagnosis. Computed tomography (CT) of the neck with contrast can help determine the severity. ${ }^{[1]}$ Radiographs of the neck and chest can also be utilized to quickly evaluate for parapharyngeal or mediastinal spread. ${ }^{[7,8]}$ In addition to trending leukocyte count, serial C-reactive protein levels may also be used as a marker of improvement. ${ }^{[9]}$

This report presents a case of Ludwig's angina successfully treated without the need for tracheostomy. Emphasis is placed on the importance of early recognition and knowledge of current management for this rare yet dangerous con-

*Correspondence: Sallie M. Long, MD; Email: sm1259@georgetown.edu; Address: Georgetown University, School of Medicine, 3900 Reservoir Road, NW Washington, D.C. 20007, USA. 
dition. Table 1 includes key clinical points to consider when confronted with similar cases.

Table 1. Key points in Ludwig's angina

- Maintain a suspicion for Ludwig's angina when a patient presents with painful submental, submandibular or floor of mouth swelling.

- Query about predisposing factors such as diabetes and HIV.

- Consult otolaryngology head and neck surgery and oral surgery immediately.

- Initiate IV antibiotics with Gram positive, Gram negative, and anaerobic coverage as soon as possible.

- Start steroids and other measures to help control upper airway edema.

- $\quad$ Admit to the ICU for airway watch even if stable.

\section{Case presentation}

A 29-year-old Hispanic male with a history of untreated hypertension arrived by helicopter to our tertiary care center from an outside community hospital for airway watch in the setting of Ludwig's angina. One week prior to presentation, he spontaneously lost his right mandibular third molar. He experienced facial pain, trismus, tongue swelling, dysphagia, and odynophagia. On the day prior to admission, he presented to an urgent care clinic and was prescribed clindamycin three times daily. His symptoms worsened, prompting him to seek evaluation at an outside hospital where he was found to be febrile to $38.3^{\circ} \mathrm{C}$ with a leukocytosis of $17,000 / \mathrm{mm}^{3}$.

Upon arrival to our hospital, his exam was notable for muffled voice, macroglossia, and a maximum interincisal distance of 20 millimeters. Pus was visualized in the socket of tooth number 32 . The submental region was firm to palpation and there was bilateral cervical lymphadenopathy. Flexible laryngoscopy noted moderate edema but otherwise a patent airway. A chest $\mathrm{x}$-ray was performed to further evaluate the airway and found no abnormalities.

He was admitted to the intensive care unit and administered intravenous (IV) dexamethasone and IV ampicillinsulbactam. His maximum interincisal distance normalized to 40 millimeters and he tolerated a clear liquid diet. Despite clinical improvement, a CT neck with IV contrast was performed in order to evaluate the tooth socket. A rim-enhancing fluid collection exceeding four centimeters was seen in the sublingual space, prompting incision and drainage and extraction of the remaining dental root (see Figure 1). Nasotracheal intubation was performed. Two incisions were made in the submandibular and submental regions and a penrose drain was placed. Blood cultures were negative and his intraoper-

Published by Sciedu Press ative culture was positive for Propionibacterium acnes. In total, the patient was treated with two days of IV dexamethasone and three days of IV ampicillin-sulbactam. After a three-day hospital stay, he was discharged home with an additional seven-day course of oral amoxicillin-clavulanate three times daily.
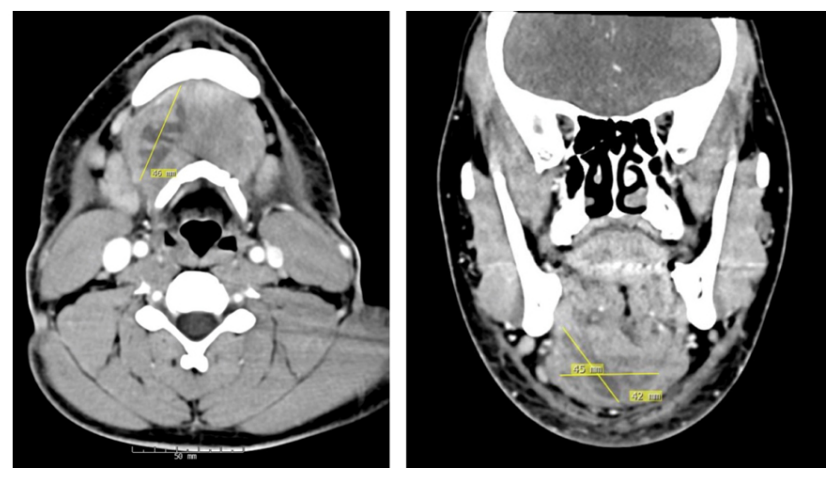

Figure 1. Axial (left) and coronal (right) $\mathrm{CT}$ images showing a $4.2 \mathrm{~cm} \times 4.5 \mathrm{~cm} \times 4.6 \mathrm{~cm}$ rim-enhancing fluid collection

\section{DiscuSSION}

This case illustrates a classic presentation of Ludwig's angina. The precipitant was infection of a mandibular molar, which is the most common site of origin. Other etiologies may include mandibular fractures and sialolithiasis. ${ }^{[1,3,4]}$ Although not the case for this patient, comorbid immunodeficiency from diabetes, HIV, or malnutrition may predispose patients and are thus important to elicit from the past medical history. ${ }^{[1,8]}$

While the advent of antibiotics drastically improved the prognosis and mortality rates of Ludwig's angina, fatal airway compromise can still occur if not promptly recognized. In progressive cases, tracheostomy and surgical debridement are required urgently. ${ }^{[1]}$ As shown in our case, however, with early recognition and medical intervention, escalation to tracheostomy can often be avoided. ${ }^{[10,11]}$ IV steroids, application of a cool humidified face tent, and epinephrine nebulizers may also assist in controlling edema that may progress to obstruct the airway. ${ }^{[8]}$

IV ampicillin-sulbactam was started immediately on presentation, though IV clindamycin or penicillin with metronidazole are alternatives. ${ }^{[4,8,12]}$ In addition to Streptococci and Staphylococci, other common microbes include Fusobacterium, Bacteroides, Prevotella and Porphyromonas. ${ }^{[1,2,13]}$ The final culture in this case was positive for Propionibacterium acnes, which is an infrequently isolated organism in cases of Ludwig's. ${ }^{[14]}$

The patient presented in this case had surgical management on hospital day three to address the abscess and extract the 
residual dental root. In this case, a demonstrable abscess warranted surgical intervention despite clinical improvement. Practice heterogeneity exists, however, surrounding the appropriate timing of surgery. It is generally accepted that any patient without clinical improvement after 48 hours of IV antibiotics should be taken for surgery. ${ }^{[7,8]}$ Others advocate for early surgical decompression regardless, as fluid collections may not be revealed until later in the disease course. ${ }^{[2,3]}$

While IV antibiotics are known as the mainstay of treatment, the duration of treatment prior to de-escalation to oral antibiotics is also variable among providers and institutions. It is generally accepted that antimicrobial therapy can be transitioned to oral administration after 48 hours of IV, though there is no set guideline. ${ }^{[15]}$ In our case, the patient was managed with three days of IV antibiotics followed by seven days of oral antibiotics.

\section{Conclusions}

This patient presented with textbook signs of Ludwig's angina in the classic setting of a preceding dental infection. This disease entity is important for physicians across all specialties to recognize and promptly initiate treatment.

\section{Disclosures}

This case report was presented as a poster at the Georgetown University Department of Medicine Research Day; May 2018; Washington, D.C., USA.

\section{Conflicts of Interest Disclosure}

The authors declare no conflicts of interest.

\section{REFERENCES}

[1] Costain N, Marrie T. Ludwig's angina. Am J Med. 2011; 124(2): 115-117. PMid:20961522. https://doi.org/10.1016/j .amjm ed.2010.08.004

[2] Boynton T, Ferneini E, Goldberg M, et al. Head, Neck, and Orofacial Infections: An Interdisciplinary Approach. St. Louis: Elsevier Health Sciences; c2015. Chapter 12, Odontogenic Infections of the Fascial Spaces; p. 203-221.

[3] Boscolo-Rizzo P, Da Mosto MC. Submandibular space infection: a potentially lethal infection. Int J Infect Dis. 2009; 13(3): 327-333. PMid:18952475. https://doi.org/10.1016/j.ijid.2008.07 .007

[4] Reynolds SC, Chow AW. Life-threatening infections of the peripharyngeal and deep fascial spaces of the head and neck. Infect Dis Clin North Am. 2007; 21(2): 557-576. PMid:17561083. https://doi.org/10.1016/j.idc. 2007.03.002

[5] Manasia A, Madisi NY, Bassily-Marcus A, et al. Ludwig's angina complicated by fatal cervicofascial and mediastinal necrotizing fasciitis. ID Cases. 2016; 4: 32-33. https : //doi .org/10.1016/j.id cr.2016.03.001

[6] Blanchard A, Garcia L, Palacios E, et al. Ludwig angina progressing to fatal necrotizing fasciitis. Ear Nose Throat J. 2013; 92(3): 102-104 PMid:23532644.

[7] Bross-Soriano D, Arrieta-Gómez JR, Prado-Calleros H, et al. Management of Ludwig's angina with small neck incisions: 18 years experience. Otolaryngol Head Neck Surg. 2004; 130(6): 712-717. PMid:15195057. https://doi.org/10.1016/j.otohns. 2003. 09.036
[8] Christian J, Goddard A, Gillespie M. Cummings Otolaryngology. 6th ed. Philadelphia: Elsevier/Saunders; c2015. Chapter 10, Deep Neck and Odontogenic Infections; p. 164-175.

[9] Bagul R, Chandan S, Sane VD, et al. Comparative Evaluation of C-Reactive Protein and WBC Count in Fascial Space Infections of Odontogenic Origin. J Maxillofac Oral Surg. 2017; 16(2): 238242. PMid:28439167. https://doi.org/10.1007/s12663-016 -0953-z

[10] Wolfe MM, Davis JW, Parks SN. Is surgical airway necessary for airway management in deep neck infections and Ludwig angina? J Crit Care. 2011; 26(1): 11-14. PMid:20537506. https ://doi .or $\mathrm{g} / 10.1016 / \mathrm{j} \cdot \mathrm{jcrc} .2010 .02 .016$

[11] Hasan W, Leonard D, Russell J. Ludwig's angina - A controversial surgical emergency: How we do it. Int J Otolaryngol. 2011; 2011: 1-4. PMid:21760800. https://doi.org/10.1155/2011/231816

[12] Rubin M, Ford L, Gonzales R. Harrison's Principles of Internal Medicine. 19th ed. New York: McGraw-Hill; c2014. Chapter 44, Sore Throat, Earache, and Upper Respiratory Symptoms.

[13] Brook I. Anaerobic bacteria in upper respiratory tract and head and neck infections: Microbiology and treatment. Anaerobe. 2012; 18(2): 214-220. PMid:22197951. https://doi.org/10.1016/j. anae robe. 2011.12 .014

[14] Brotfain E, Koyfman L, Saidel-Odes L, et al. Deep neck infection and descending mediastinitis as a complication of Propionibacterium acnes odontogenic infection. Case Rep Infect Dis. 2015; 2015: 1-3.

[15] Farish S. Current Therapy in Oral and Maxillofacial Surgery. St. Louis: Elsevier Saunders; c2012. Chapter 118, Ludwig's angina; p. 1092-1098. 